\title{
Language Contact in Modern Uyghur. By Aminem Memtimin. Turcologica 108, Harrassowitz Verlag: Wiesbaden, Germany, 2016, 245p.; ISBN: 978-3-447-10631-3
}

\author{
Giulia Cabras \\ Institute of Turkic Studies, Freie Universität Berlin, 14195 Berlin, Germany; cabras.juli@gmail.com
}

Received: 10 August 2018; Accepted: 25 October 2018; Published: 2 November 2018

The study of language contact can be approached from different perspectives, such as in terms of diachronic development, synchronic variation, structural change, or social meanings.

The work under review, Language contact in Modern Uyghur by Aminem Memtimin, successfully balances the perspectives cited above, taking Modern Uyghur as the object of study. Modern Uyghur is a Turkic language spoken mainly in the Xinjiang Uyghur Autonomous Region of the People's Republic of China and belonging to the southeast Turkic languages group (known also as Chagatay or Qarluq languages). It derives from Chagatay and is known for its contacts with several languages spoken in Central and Eastern Asia, in particular, Persian, Arabic, Russian, Mongolian, and Chinese.

The synchronic and diachronic dimensions are woven together in this work in two ways. Regarding language contact, the book deals with languages that have had a strong impact on the historical development of the Uyghur language-Arabic, Persian, Mongolic, and Russian—as well as with Chinese, which plays a major role nowadays.

Regarding the Uyghur language itself, the work takes into account the predecessor of Modern Uyghur, Chagatay, a written language employed in Central Asia between the fifteenth and twentieth centuries, as well as its different contemporary varieties with their geographical extension, historical heritage, and social functions.

The research is based on empirical data comprising lexical material from several dictionaries of Modern Uyghur and of its contact languages. It also makes use of recordings of colloquial Uyghur collected by the author, as well as material extracted from internet websites. Thus, the corpus includes not only the standardized language found in dictionaries (rightly described by the author as an "abstraction") but also current formal and informal speech, as used in everyday life.

The book is structured in seven chapters. The first chapter is an introduction to the work, which focuses on the theoretical background, previous studies, data collection, and an overview of Uyghurs and their language. Following Winford's and Weinreich's approaches, the study addresses the linguistic and sociolinguistic perspectives, as well as some theoretical issues related to universals in language contact. Being in contact with Semitic, Iranian, Mongolic, Slavic, and Sinitic languages, Uyghur can constitute an appealing case study to further investigate constraints and motivations for change in contact situations.

Although Memtimin's work is rooted in empirical research, it also draws from different theoretical approaches, such as Haugen's notions on borrowing, Johanson's code-copying model, and van Coetsem and Zuckermann's transfer theory. This framework allows the author to discuss differences in the terminology and in contact situations, such as typological similarities, the borrowability of grammar and lexicon, and social prestige.

In the part dedicated to previous research, the author gives a comprehensive account of the literature regarding language contact in the Uyghur language. Examining works published since 
the 1990s in English, Uyghur, and Chinese, the author highlights three main problems: the need to increase research on Mongolic-Uyghur language contact; some superficial conclusions in the study of etymologies; and some confusion in the contact processes between diachronic developments and synchronic usages.

The introductory part ends with some fundamental characteristics of Uyghurs and the Uyghur language. This section mentions the ethnic and linguistic richness of Xinjiang as well as the diversity of Uyghur dialects, sociolects, and technolects. In the following chapters, the author deals in several places with the internal variation of the language and its different domains of usage. In the current Xinjiang sociolinguistic context, Chinese acts as a high variety, given its strong presence in the media and education, but is also used in everyday communication. This kind of information provided by the author, a native speaker of Uyghur who knows the linguistic community from an emic standpoint, is valuable in understanding the Chinese influence in Uyghur spoken and written practices considered at the end of the book.

The next chapters are dedicated to the languages involved in contact with the Uyghur language: Persian, Arabic, Mongolic, Russian, and Chinese. For each of them, the author first presents the historical and cultural background of the contact and focuses subsequently on the integration of foreign elements on the phonetic, morphological, syntactical, semantic, and pragmatic levels, as well as on the word classes involved, providing the reader with a multi-layered and extensive image of the contact between Uyghur and these languages.

In terms of Arabic and Persian influence in Uyghur, the author highlights the importance of dealing with these two languages separately and therefore does so in two separate chapters (Persian in Chapter 2 and Arabic in Chapter 3). Even though several Arabic terms came into Uyghur through the mediation of Persian, the languages emerge in different ways in Uyghur. This is because of their grammatical differences as well as the nature of the contact: while Persian influence involves close personal and daily contact with Persian-speaking communities, a characteristic that is reflected in today's social and cultural habits (including politeness and literary registers), Arabic influence is more restricted to the domains of religion, literary language, and sciences.

Regarding Persian, the author first gives a comprehensive overview of its historical role as a lingua franca in Central Asia, which started in the seventh century, continued with the emergence of the New Persian language in the ninth century and the influence of the Persian-Islamic civilization in the Qarakhanid empire, and reached its peak with Chagatay literature in the fourteenth to fifteenth centuries. The examination of the socio-cultural factors relating to language contact with Persian and Arabic does not overshadow the attention dedicated to phonetics and morphosyntax, as shown in the description of vowels and consonant changes and in the account of the different word classes involved (such as pronouns, postpositions, prepositions, conjunctions), word formation, and new syntactic means (such as the izafe construction, some binomes, and right-branching subordinate clauses, inherited from Persian through Chagatay).

Chapter 4 is dedicated to the contact between Uyghur and Mongolic. Leaving aside the debate between supporters of the contact-induced change theory and of the Altaic theory, the author focuses mainly on the direct and indirect influence of Mongolic, starting from the thirteenth century, in particular on specific Uyghur dialects, such as those spoken in Ghulja, Qumul, Turpan, and Lopnor. Considering Uyghur diversity allows the author to connect linguistic evidence with the history of the region (such as Ghulja as the main center under Jungar domination, the survival of Buddhism in certain areas of the regions during the expansion of Islam, and Mongolic migrations), and Xinjiang toponomy.

Working on the influence of a language that is typologically similar to Uyghur requires first understanding which words are of Mongolic, not Turkic, origin, and then when and from which stage of the Mongolic language they were borrowed (e.g., pre-classical Mongolic or classical) or through which specific Mongolic dialects.

The author identifies several semantic domains where Mongolic copies can be found: animals and plants, hunting and fishing, toponyms, natural phenomena, and household objects. This shows 
how the socio-cultural background of the contact was different from that characterizing contact with other languages, such as Arabic or Persian.

An important contribution made by this chapter is to present a topic that has been the least studied in research on Uyghur language contact since more attention has been given to the historical Arabic-Persian influence and the current Chinese influence. The clear and documented explanations make the chapter accessible, even to an audience not familiar with Mongolic languages.

Chapters 5 and 6 are dedicated to language contact in the twentieth and twenty-first centuries, with the influence of Russian and Chinese respectively.

With regard to the Russian influence, the author draws attention to Russian relationships with Central Asia around the end of the nineteenth century, the Jadid movement, and Soviet penetration of Central Asia as key events for the socio-historical context of the linguistic contact. The linguistic analysis is organized into phenomena of phonetic adaptation (i.e., resolution of consonant clusters and consonant changes), processes of word formation, and semantics (with a classification of the Russian copies into 27 groups, among them terms related to politics, economics and finance, transport, food, media, and sciences).

The author also specifies the differences between spoken and written Russian, which can also be identified in the Russian copies found in Uyghur. This gives evidence of Russian words that were used in daily life, and others that were introduced through the medium of writing or related to lexical domains not often used in colloquial language.

As far as the Chinese influence is concerned, the study focuses on modern copies and therefore on the intense contact developed during the last two centuries because of political and social changes that have taken place in the Xinjiang region. Nonetheless, the author devotes a section to the historical Chinese influence, mentioning terms found in Old Uyghur religious and lay texts, as well as in the Qing dynasty's pentaglot dictionary.

A difference stressed in these last chapters is that, while Russian copies are found in particular domains, such as politics, sciences, and culture, because of Russia's role as a bridge between Europe and Central Asia, the Chinese ones are present in most of the word classes (nouns, adjectives, adverbials, quantifiers and, although only in colloquial Uyghur, numerals), registers, and semantic fields, including idioms, new expressions, and structural calques in the media.

Also in this part of the book, linguistics merges with sociolinguistics. In describing the different vowel and consonant changes that take place in the integration of Chinese terms in Uyghur, the author points out the tendency to pronounce the words with Chinese phonetic features, because of increasing bilingualism and also as a "showing off" attitude to demonstrate good knowledge of Chinese. Another point made is the identification of two different sources for the Chinese copies, the local variety of Chinese and Standard Chinese; this is important in order to get an idea of the complexity of the linguistic environment in Xinjiang and to better understand the realization of Chinese terms in Uyghur speech.

Other sections address a topic of great interest in contact linguistics and typology: the formation of so-called bilingual verbs or mixed verbs. The author presents different means of integration of foreign verbs in Uyghur through syntactic, analytic, and mixed strategies (including some consideration of the formations consisting of a monosyllabic verb with the Chinese form $l e$ and the auxiliary qil- 'to do').

Because of its high status as national language promoted by the state, Chinese is frequently used to express new concepts and objects related to information, technology, new trends, slogans, and political terms. As with Russian during the twentieth century, the influence of Chinese is a result of linguistic, social, and cultural contact, but is also controlled by state and regional language policies. The Nationalities' Language and Writing Service Committee plays an important role in accepting and diffusing new terms, as well as their spelling and pronunciation. The chapter ends with a brief introduction to code-switching between Uyghur and Chinese, with extracts of conversations that give a glimpse into how language contact and bilingualism take place in Uyghurs' daily life and language practices today. 
In the last chapter, the author provides concluding comments on language contact in Modern Uyghur and on the way linguistic features are incorporated into the target language, including factors such as linguistic structure, language status, language planning, and education.

The book is a well-documented synthesis and analysis of language contact phenomena in the Uyghur language, essential to understanding the historical development of Modern Uyghur as well as the influence of Persian, Arabic, Mongolic, Russian, and Chinese on the different levels of the language, from phonetics to pragmatics.

I fully recommend this book to anyone interested in Turkic linguistics, language contact, historical linguistics, and sociolinguistics, as well as to those working on Central Asia and Asian studies who wish to better understand the social and cultural dynamics related to Chinese Inner Asia through the history of the Uyghur language.

Funding: This research received no external funding.

Conflicts of Interest: The author declares no conflict of interest.

(C) 2018 by the author. Licensee MDPI, Basel, Switzerland. This article is an open access article distributed under the terms and conditions of the Creative Commons Attribution (CC BY) license (http:/ / creativecommons.org/licenses/by/4.0/). 